\title{
ASPEK TATAKRAMA MASYARAKAT SUNDA DALAM BABASAN DAN PARIBASA
}

\author{
Ade Sutisna \\ Departemen Pendidikan Bahasa Darerah FPBS UPI \\ Poe-el: ade.sutisna@upi.edu
}

\begin{abstract}
Abstrak
Penelitian ini mendeskripsikan aspek-aspek tatakrama masyarakat Sunda dengan merujuk pada budaya babasan dan paribasa Sunda. Babasan dan paribasa Sunda sendiri merupakan produk budaya masyarakat Sunda yang berwujud dalam bentuk frasa dan klausa atau kalimat yang disampaikan secara turun temurun sejak lama sebagai salahsatu cara masyarakat Sunda dalam mengedukasi saudaranya dalam hal berintraksi sosial. Dalam prosesnya, penelitian ini menggunakan metode deskriptif analitis sebagai cara untuk mendapatkan gambaran tentang aspek yang dimaksud. Adapaun data yang digunakan adalah data primer yang merupakan babasan dan paribasa Sunda yang telah didokumentasikan oleh para penulis budaya Sunda. Kemudian data tersebut dianalisis berdasarkan kajian makna dan intervensi peneliti terhadap makna tersebut. Dalam perjalanan panjangnya, peneliti menemukan beberapa babasan dan paribasa Sunda yang memilki makna nilai-nilai tatakrama untuk interaksi sosial. Di antara aspek nilai tatakrama yang diperoleh di antaranya adalah: 1) aspek tatakrama berbahasa, 2) aspek tatakrama kinetis, dan 3) aspek tatakrama hubungan sosial. Setelah dianalisis dan di deskripsikan, selanjutnya didapati adanya pola tatakrama masyarakat Sunda yang mencakup ketiga aspek tersebut yang harus hadir secara bersamaan dalam satu interaksi sosial. Pola tersebut dirangkum dalam lima istilah kata yang terdiri atas: 1) wiwaha, 2) wibawa, 3) wirasa, 4) wirahma, dan 5) wiraga.
\end{abstract}

Kata kunci: Tatakrama Sunda, Babasan Sunda, Paribasa Sunda.

\section{SUNDANESE SOCIETY ASPECTS OF MANNERS IN BABASAN AND PARIBASA}

\begin{abstract}
This study describes Sundanese aspects of manners by referring to babasan and paribasa (lit. expression and proverb) in Sundanese culture. Babasan and paribasa are tangible products of Sundanese culture in the forms of phrases and clauses, or sentences, which are delivered from generation to generation extensively. They are ways to educate Sundanese people in social interaction. This research employs descriptive analysis method to get an overview of aspects contained in babasan and paribasa. The primary data are babasan and paribasa that have been documented by the authors of Sundanese culture. Then the data was analyzed based on the study of meaning and the intervention of meaning. This study found some Sundanese babasans and paribasas as having the meaning of manner values in social interaction. The aspects of manner values found, among others, are (1) aspects of language etiquette, (2) aspects of kinetic manners, and (3) the aspects of social relation manners. After being analyzed and described, the study found the Sundanese pattern of manners that includes three aspects. The pattern must present simultaneously in a social interaction. The pattern is summarized in five terms: 1) wiwaha; 2) wibawa; 3) wirasa; 4) wirahma; and 5) wiraga.
\end{abstract}

Keywords: Sundanese Manners, Sundanese Babasan, Sundanese Paribasa. 


\section{PENDAHULUAN}

Terjadinya perubahan terhadap tatanan sosial merupakan suatu hal yang tidak bisa dipungkiri. Hal tersebut merupakan sebuah keniscayaan kemajuan jaman yang dilandasi oleh adanya perkembangan ilmu pengetahuan dan teknologi. Oleh sebab itu, maka tugas manusialah selanjutnya mengisi dan mengimbangi berbagai perubahan dan kemajemukan tersebut menjadi sebuah peradaban yang lebih seimbang.

Sebagaimana yang telah diketahui bersama bahwa perubahan tatanan sosial telah membawa dampak terhadap sikap dan prilaku manusia itu sendiri. Sebuah dampak yang paling dominan dan dirasakan langsung adalah pengaruh negatif terhadap sikap dan prilaku masyarakat, diantarananya adalah prilaku individualisme, hedonisme, dan sarkasme yang menjurus pada perpecahan antar masyarakat. Intinya bahwa telah terjadi krisis moralitas di tengah-tengah masyarakat Indonesia saat ini, yaitu hilangnya nilai-nilai kehidupan manusia sebagai mahluk sosial yang saling membantu dan saling menghargai satu sama lain. Semua itu sesungguhnya bisa berakar salahsatunya dari persoalan budi pekerti. Kehilangan nilai budi pekerti telah berdampak pada hilangnya keseimbangan kehidupan sosial masyarakat. Ketimpangan terjadi hampir disemua sisi dan sendi kehidupan saat ini, yang akhirnya menyebablan terjadi konflik horisontal di tengah-tengah masyarakat. Ketika kehidupan sosial mulai tidak seimbang, maka sangatlah mudah dimanfaatkan oleh pihakpihak lain yang berkepentingan untuk mengendalikan manusia pada arah atau tujuan tertentu. Dengan alasan ideologi, mereka yang berkepentingan menawarkan berbagai jalan untuk menuju alur kehidupan yang sesungguhnya bertentangan dengan nurani karena keterpaksanaan. Akhirnya bagi mereka yang tidak memiliki kekuatan niali dalam dirinya akan terjebak dan masuk pada situasi lingkungan yang merugikan.

Masalah tersebut di atas tentunya saja harus menjadi perhatian serius semua pihak, melalui kesadaran kolektif berbagai lapisan masyarakat sangat dibutuhkan untuk menumbuh kembangkan konvensional kebudayaan. Dengan demikian maka akan tumbuh kesepakatan untuk saling menjaga, menghargai, menolong, dan saling mengasihi di tengah-tengah lingkungan sosial. Salahsatu aspek yang dianggap dapat menumbuhkan sikap tersebut adalah pendidikan moralitas yang bersumber pada nilai-nilai agama dan kebudayaan. Nilainilai yang bersumber dari keagungan agama tentunya saja sebuah hal yang bersifat mutlak dan tidak diragukan. Lain halnya dengan kebudayaan yang memiliki sifat konvensional masyarakatnya itu sendiri.

Aspék budaya yang dimaksud dalam pembahasan ini adalah tingginya nilai-nilai tatakrama sosial masyarakat yang hadir dan disepakati oleh masyarakat itu sendiri sebagai jembatan dan aturan lalulintas interaksi sosial. Munculnya tatakrama sebagai pengatur manusia dalam berinteraksi dengan lingkungannya. Dengan demikian maka diharapkan kehidupan sosial dapat berlangsung dengan tertib, aman, terkendali, damai, dan harmonis.

Salahsatu aspek tatakrama yang menjadi kebanggan khususnya bagi masyarkat Sunda adalah tatakrama yang muncul dalam babasan dan paribasa. Keduanya merupakan hasil proses kebudayaan masyarakat Sunda dalam bentuk pakeman-pakeman bahasa atau ungkapanungkapan masyarakat Sunda terdahulu. Pada masanya, babasan dan paribasa merupakan sebuah usaha yang dilakukan oleh masyarakat Sunda untuk mengedukasi sesama dalam segala aspek kehidupan. Masyarakat Sunda lebih senang menggunakan "permainan" bahasa sebagai alat untuk "menyindir" atau memberitahu tentang suatu hal dengan cara yang halus tanpa menyakiti perasaan orang lain. Hal tersebutlah yang saat ini jarang diketemukan dalam kehidupan sosial masyarakat. Oleh sebab itu maka perlu dihadirkan berbagai cara dan usaha untuk menghidupkan kembali keluhuran nilai-nilai 
tatakrama dan budi pekerti yang bersumber dari nilai-nilai kebudayaan lokal.

Deskripsi di atas merupakan penjelasan kunci utama kehidupan sosial masyarakat Sunda, yaitu tatakrama dan keluhuran budi. Selanjutnya tugas kita adalah bagaimana menentukan sikap dan prilaku sosial yang baik dan bernilai tersebut selalu hadir dalam interaksi sosial. Ketika membahas babasan dan paribasa Sunda, yang kerap muncul dalam pikiran kita adalah bagaimana mengajarkan babasan dan paribasa tersebut kepada siswa? Hal tersebut tidaklah salah, akan tetapi alangkah baiknya jika menyampaikan babasan dan paribasa kepada siswa tidak sebatas pada pengenalan dari sisi budaya, melainkan niali-nilai yang terkandung di dalamnya dan formulasinya dalam kehidupan sosial kemasyarakatan. Dengan demikian maka mengajarkan babasan dan paribasa kepada siswa akan berjalan secara utuh dan lebih bermakna.

Selanjutnya, masalah yang akan dibahas dalam penelitian ini adalah mendeskripsikan aspek-aspek tatakrama masyarakat Sunda yang muncul dalam babasan dan paribasa yang meliputi aspek tatakrama bahasa dan non bahasa. Masalah ini lebih rinci membahas tentang aspek tatakrama bahasa, tatakrama kinetis, dan tatakrama interaksi sosial. Dengan demikian diharapkan tujuannya akan muncul pola tatakrama bagi masyarakat Sunda yang bersumber pada babasan dan paribasa Sunda sebagai produk budaya buhun.

\section{METODE}

Metode yang digunakan dalam penelitian ini adalah metode deskripsi. Metode ini digunakan untuk mendeskripsikan aspek tatakrama masyarakat Sunda dalam babasan dan paribasa Sunda.

\section{HASIL DAN PEMBAHASAN}

Sacara étimologis tatakrama berasal dari kata 'tata' dan 'krama' yang merupakan bahasa sangsekerta. Kata 'tata' memilki makna adat atau aturan, sedangkan krama memiliki arti sopan. Dengan demikian tatakrama dapat diartikan secara umum merupakan sebuah sistem dari seluruh kebiasaan tata cara manusia di dalam lingkungannya atau dapat pula diartikan sebagai aturan sopan santun yang sepakat untuk dilakukan oleh masyarakat.

Selain istilah tatakarama dan sopan santun, dalam berinteraksi sosial dikenal pula dengan istilah etiket. Etiket yang berasal dari bahasa Perancis memiliki makna tata cara pergaulan yang baik antar manusia. Secara keseluruhan berbagai istilah tersebut sesungguhnya memiliki makna yang sama yaitu menata sebuah peraturan pergaulan manusia yang bermoral dan berkiblat pada aturan agama, budaya, dan susila. Magnis (1985) menjelaskan bahwa sifat dasar sebuah etika yaitu sifat kritis, artinya bahwa etika memiliki tugas untuk mempermasalahkan norma-norma yang berlaku di sebuah komunitas masyarakat tertentu. Apakah yang menjadi dasar menyebabkan norma tersebut dapat diterima oleh sebuah komunitas. Itulah sesungguhnya menjadi tugas utama sebuah etika. Dengan demikian dapat diartikan bahawa sebuah etika dapat berlaku ketika ada kesepakatan dari masyarakat yang menggunakannya. Hal tersebut penting untuk menjaga agar sebuah etika tidak berperan terbalik sebagai sebuah aturan yang menyebabkan konflik dikemudian hari. Oleh sebab itu, maka etika harus menjadi pengantar masyarakat pada sikap dan cara berpikir kritis dan rasional. Sikap dan cara berpikir tersebut selanjutnya harus bisa menjadi pegangan untuk menentukan langkah-langkah strategis selanjutnya yang bertanggungjawab dan rasional. Selanjutnya Magnis (1985) juga menjelaskan bahwa etika merupakan cabang ilmu filsapat yang membahas tentang pandangan-pandangan dalam bidang moralitas. Oleh karena pandangan-pandangan tersebut dijelaskan dalam bentuk pernyataan-pernyataan, maka yang menjadi obyek dari etika adalah merupakan pernyataan-pernyataan moral. Intinya adalah etika dapat dilihat dan dipahami dari pernyataan-pernyataan yang 
muncul di masyarakat baik yang benar dan baik maupun yang buruk. Adapun pernyataan yang dimaksud adalah: 1) ada pernyataan yang menunjukan bahwa salahsatu prilaku tersebut sesuai atau tidak dengan norma-norma moralitas yang berlaku dan bersipat wajib atau harus, 2) pernyataan yang menilai kepribadian seseorang itu baik, buruk, jahat, atau menyenangkan, hal tersebut termasuk pada pernyataan memberikan pertimbangan moral, 3) pernyataan-pernyataan yang merupakan memberikan penilaian pada halhal yang bersifat non moralitas, umpamanya memberikan pujian, tutur kata yang baik, anggukan kepala, dll.

Menambahkan apa yang diuraikan tersebut di atas, sesungguhnya tata cara pergaulan itu tidak dapat diteliti begitu saja, melainkan harus dibarengi dengan kesadaran yang muncul dalam hati, tidak dibuat-buat, dan dilaksanakan dengan penuh kesadaran dan keikhlasan. Dengan cara demikian maka tatakrama akan tumbuh dan berkembang dalam diri setiap insan manusia secara utuh dan permanen (Rachim, 1983:3). Adapun tujuan dari menanamkan tatakrama secara utuh dan permanen di setian insan manusia tersebut adalah untuk membangun watak dan mental manusia agar menjadi pribadi-pribadi yang yang baik (Wirahadikusumah, 1985:1). Berbicara tatakrama sama halnya membahas kesadaran manusia untuk menandakan mana yang baik dan mana yang buruk. Walaupun setiap kelompok masyarakat tertentu memiliki tatakrama yang berbeda, pada dasarnya sama agar dapat hidup sesuai dengan aturan atau adat yang dianggap baik oleh masyarakat tersebut.

Pendapat lainnya yang memandang pentingnya tatakrama dalam kehidupan sosial muncul dari Sudaryat (2015:228) yang menjelaskan bahwa pola kebiasaan prilaku itu sangatlah baik dan terpuji apabila dilakukan dalam komunikasi dan interaksi sosial yang berdampak pada munculnya rasa simpati, menyenangkan dan tertarik, bangga dan hormat, dan pada akhirnya menimbulkan kesan indah, andalemi, sopan, halus, luwes, gagah, sportif, dan santun. Kebiasaan dalam melakukan tindakan yang baik (terpuji) dapat memunculkan kepekaan rasa, ahlak yang baik, keluhuran budi, dan pribadi yang mantaf. Sebaliknya jika yang muncul adalah kebiasaan prilaku yang buruk, maka akan menghadirkan ahlak yang buruk, kasar, tidak memiliki perasaan, budipekerti yang rendah, serta mental yang rendah. Selanjutnya jika muncul sikap ingkar terhadap sopan santun dalam komunikasi sosial akan menimbulkan kekecewaan, kegelisahan, dan keheranan yang dapat menimbulkan hilangnya kepercayaan, simpati, dan rasa hormat.

Menurut Yudibrata (1984), tatakrama dalam pergaulan sosial memiliki fungsi dan peran yang tidak sederhana, melainkan berperan besar dalam mengatur tatanan kehidupan sosial masyarakat. Adapun fungsi tatakrama yang dimaksud adalah:

a) fungsi personal, adalah fungsi tatakrama untuk menunjukan kedewasaan pribadi;

b) fungsi sosial, adalah tatakrama untuk menunjukan keluwesan dalam pergaulan dan komunikasi;

c) fungsi kultur, adalah untuk menunjukan keluhuran budi dan kedewasaan berprilaku;

d) fungsi edukasional, adalah untuk menunjukan tingkat keilmuan dan keterpelajaran;

e) fungsi integratif, adalah untuk menunjukan keterlibatan dalam satu sistem kemasyarakatan;

f) fungsi instruméntal, untuk menunjukan tingkat kehalusan sebuah alat untuk mencapai tujuan;

Berdasarkan bahasan tersebut, maka tidak ada alasan untuk setiap individu mengingkari tatakrama dalam pergaulan sosial. Dengan cara memahami fungsifungsi tatakrama, maka diharapkan setiap pribadi individu dapat menempatkan dirinya sesuai dengan waktu, tempat, dan tujuan dalam membangun komunikasi dan 
interaksi sosial. Umar Wirahadikusumah dalam Sudaryat (2015) menjelaskan bahawa dasar dari sopan santun adalah memberikan perhatian pada perasaan orang lain, dan sopan santun berlaku bagi seluruh tingkatan manusia baik anak, remaja, dewasa, maupun orang tua. Oleh sebab itu, maka sopan santun harus menjadi kebiasaan setiap individu sejak kecil dengan mencontoh prilaku yang diperlihatkan oleh kedua orang tuanya.

\section{Aspek-aspek Tatakrama Sunda}

Menurut Yudibrata dalam Sudaryat (2015:230), tatakrama Sunda memiliki beberapa jenis dan dimensi, di antarannya: 1) dimensi waktu; 2) dimensi ruang, tempat, dan geografis; 3) dimensi struktur dan status sosial; dan 4) dimensi fungsi cara menggunakannya. Yang dimaksud dengan dimensi waktu adalah menunjukan waktu tempo dulu, sekarang, dan masa yang akan datang. Diménsi ruang, tempat, dan géografis menunjukan rumah dan di luar rumah. Diménsi struktur dan strata sosial berpusat pada sesama, atasan, bawahan, wanita, laki-laki, profesi tertentu, anakanak, dll. Sedangkan diménsi fungsi cara menggunakannya bertolak pada situasi formal dan non formal.

\section{Aspek Tatakrama bahasa}

Tatakrama bahasa memiliki hubungan dengan situasi dan kondisi komunikasi seseorang. Dalam hal ini, tatakrama bahasa menegaskan bahwa dalam hal berbicara sudah seharusnya memperhatikan beberapa aspek, di antaranya adalah: 1) aspek penutur; 2) aspek mitra tutur; 3) aspek tema tuturan; 4) aspek tempat terjadinya komunikasi; 5) aspek waktu berbicara; 6) aspek tujuan berbicara; 7) aspek situasi ketika berbicara.

\section{Aspek Tatakrama Kinetis}

Yang dimaksud dengan tatakrama kinetis adalah segala hal yang mengatur penampilan dan tingkah laku yang berhubungan dengan gerak ragawi (kinestik). aya hubunganana jeung gérak ragawi (kinésik), misalnya: mimik wajah, cara berdandan, memelihara kasehatan, cara berjalan, dan cara-cara lainnya yang menunjukan segala hal yang berhubungan dengan gerak ragawi (Djundjunan, 2011:25).

\section{Aspek Tatakrama Pergaulan}

Pergaulan merupakan kegiatan interaksi antara seseorang dengan orang lain. Dalam hal kegiatan interaksi tersebut sudah barang tentu melibatkan beberapa unsur, baik unsur internal maupun eksternal. Yang dimaksud dengan unsur internal dalam pergaulan adalah unsur yang sering muncul dari diri pribadi termasuk bahasa, perasaan, dan pengetahuan Sedangkan faktor eksternal merupakan pengaruh dari keadaan mitra tutur, tempat, lingkungan, budaya sosial, dan geografis. Menurut Sudaryat (2015: 231), tatakrama gaul meliputi: 1) dimana kita berada, 2) bagaimana situasi dan keadaan di sekitar kita, dan 3) siapa yang berada di hadapan kita.

\section{Tatakrama Hidup di Masarakat}

Manusa sebagai mahluk sosial memilki makna bahwa manusia tidak dapat hidup menyendiri, melainkan membutuhkan peran dari orang lain sebagai bagian dari kebutuhan hidup kita. Dalam hal berinteraksi sosial, manusia memerlukan berbagai aturan-aturan yang mengatur lalu lintas kehidupan manusia di tengah-tengah masyarakat yang majemuk. Dalam hal ini kembali tatakrama memiliki peran untuk mengatur tatanan sosial tersebut. Adapaun tatakrama sosial meliputi:

1) menghargai orang lain;

2) bisa menempatkan diri untuk keluarga, lingkungan, dan masyarakat;

3) bijaksana terhadap lingkungan sekitar;

4) bisa memutuskan sebuah perkara secara adil;

5) mau bergotong royong;

6) tidak mau menang sendiri;

7) memiliki rasa malu;

8) selalu bersih hati; 
9) mau berkorban untuk kepentingan umum;

10) rajin dan mau belajar

11) saling mengingatkan dalam kebaikan

\section{Babasan dan Paribasa Sunda}

Babasan dan paribasa Sunda termasuk pada pakeman bahasa yang dimilki oleh masyarakat Sunda. Dari pakeman tersebut lahirlah berbagai nilai-nilai kehidupan sosial, termasuk tatakrama dan etika. Babasan dan paribasa merupakan bentuk budaya kolektif masyarakat Sunda atau disebut dengan foklor yang berasal dari bentuk lisan. Hal tersebut ditegaskan oleh Danandjaja (2007:21), bahwa bentuk (genre) foklor lisan yang berada di wilayah Indonesia itu terdiri atas: a) bahasa rakyat (folk speech); (b) ungkapan tradisional contohnya paribasa, papatah, pemeo; c) tatarucingan; d) puisi rakyat contohnya pantun (sisindiran), gurindam, dan syair; e) cerita prosa rakyat, seperti mite, legenda, dan dongéng, serta f) lagu rakyat. Babasan dan paribasa bisa juga disebut peribahasa, pakeman basa, atau idiom. Selanjutnya menurut Sudaryat (1997:91) menjelaskan bahwa yang dimaksud idiom (pakeman basa) adalah bentuk bahasa yang khas dan mandiri, serta arti yang dikandungnya tidak dapat diartikan sebagaimana mestinya berdasarkan arti tata bahasa atau ditafsirkan berdasarkan kandungan unsur-unsur pembentuknya. Selain itu, idiom juga memiliki arti merupakan pola-pola struktural yang tidak sama dengan tata bahasa pada umumnya, biasanya dalam bentuk frasa serta arti yang dikandungnya tidak bisa ditafsirkan secara umum (Kéraf, 2010:109)

Babasan dan paribasa sangat kaya dengan kandungan makna secara simbolis (siloka), oleh sebab itu maka melalui babasan dan paribasa kita dapat menyampaikan maksud dan tujuan dengan cara tidak langsung serta menyingkat maksud perkataan yang panjang. Ihwal lahirnya babasan dan paribasa tidak dapat diteliti kapan mulai ada dan siapa yang menciptakannya.

Selain babasan, dikenal pula istilah lain yang disebut dengan paribasa yaitu rangkaian kalimat (klausa) yang kata serta susunannya sudah berdiri sendiri, memiliki maksud yang sudah jelas, dan biasanya memiliki makna membandingkan atau simbol-simbol kehidupan manusia (Sudaryat, 1997:99).

\section{Tatakrama Dalam Babasan Dan Paribasa Sunda}

Berdasarkan hasil analisis data, ditemukan beberapa aspek tatakrama yang muncul dalam babasan dan paribasa. Aspek-aspek tersebut pada dasarnya memberikan informasi kepada setiap orang untuk selalu memperhatikan kesantunan dalam berbahasa, kinetis, dan dalam melakukan interaksi sosial kemasyaraktan. Dalam aspek bahasa, tatakrama faktor penutur muncul di antaranya:

\section{Dibeuweung diutahkeun............. 'dikumur dimuntahkan' Dipikir dibulak-balik.... . 'dipikir bolak-balik'}

Babasan tersebut di atas menunjukan bahwa setiap penutur hendaknya menggunakan pikirannya dengan bijak dalam setiap perkataan atau ujaran yang akan disampaikan. Adapun maksud dan tujuannya adalah agar setiap mitra tutur tidak merasa tersinggung atau dirugikan oleh setiap tuturan yang disampaikan kepadanya. Hal ini jelas menandakan bahwa kesantunan dalam bertutur harus menjadi pegangan setiap penutur dalam berkomunikasi. Selain data tersebut di atas, contoh data lainnya yang menunjukan tatakrama berbahasa muncul pada babasan berikut ini. 
Biwir nyiru rombéngeun

Resep ngucah ngacéh kagoréngan batur

Membicarakan kejelekan orang lain tentu bukanlah hal yang baik, karena selain akan menimbulkan konflik sosial juga akan menimbulkan penilaian negatif pada si penuturnya. Hal ini ditegaskan oleh data tersebut di atas, sangat jelas bahwa setiap
.'Bibir nampan yang rombeng'

suka membicarakan kejelekan orang lain

penutur sangat dilarang sekali untuk membicarakan kejelekan orang lain. Di bawah ini ada beberapa contoh babasan dan paribasa lainnya yang menunjukan kesantunan bagi seorang penutur.

Asa aing uyah kidul.......................................Ini aku garam dari selatan

Asa jadi pangpunjulna................................merasa lebih unggul dari yang lain

Bisi aya cai ti cai ngeusan mandi................takut ada air dari air sudah mandi

Bisi aya kasigeung atawa katoél rasana..... Khawatir ada yang tersinggung hatinya

Gedé bobot pangayomna.

Besar pertimbangannya

Gedé tinimbangan. besar pertimbangan

Selain tatakrama bahasa, dalam babasan dan paribasa pun diketahui adanya unsur tatakrama kinetis, yaitu kesantunan yang harus dimiliki oleh setiap orang dalam

memeperlihatkan gerak ragawinya (kinetis) ketika interaksi sosial berlangsung. Umpamanya pada data berikut ini.

Ambekna sakulit bawang

Babari ambek.

.Marahnya setipis kulit bawang mudah marah

Orang yang mudah sekali untuk marah biasanya muncul di tengah-tengah lingkungan masyarakat kita. Sikap demikian sesungguhnya hanya akan merugikan dirinya sendiri dan orang disekitarnya. Dengan demikian maka tidak akan tercipta suasana yang harmonis sesuai

dengan prinsip-prinsip etika sosial. Berdasarkan hal tersebut, maka data babasan dan paribasa di atas jelas menunjukan kepada kita agar tidak menjadi seorang pemarah atau mudah marah. Data lainya yang menunjukan kesantunan kinetis di antaranya adalah sebagi berikut.

Bisa mihapekeun manéh. dapat menitipkan diri

Hadé tingkah polahna jeung budi basana, nepi ka batur resepeun

Ginding kekempis. Gaya kekempis

Ginding tapi teu boga duit. Gaya tapi tidak punya uang

Hapa héman. Hampa kasih sayang

Taya panarimaanana, taya pamales budi ka nu geus nyieun kahadéan

Setelah unsur kinetis, unsur hubungan sosial menjadi bagian dari terwujudnya tatakrama sosial, yaitu bagaimana kesantunan bisa dihadirkan dalam interaksi sosial. Kesantunan ini meliputi tatakrama yang mengatur terjadinya relasional antar manusia dalam suatu kelompok tertentu. Kesantunan yang muncul dalam aspek ini 
terdapat pula dalam babasan dan paribasa

berikut ini.

Sunda. Hal tersebut dilihat dari contoh data

\section{Kaduhung tara ti heula}

Ngarasa hanjakal mah moal saméméh migawé

Data di atas memiliki makna bahwa setiap perbuatan yang dilakukan akan memiliki konsekwensi tersendiri, dan tugas kita adalah untuk selalu memperhitungkan resiko yang akan didapat ketika kita bertindak sesuatu. Perhitungan tersebut hendaknya dilakukan secara matang, agar tidak ada rasa menyesal dikemudian hari. Itulah pesan makna yang terkandung dalam data tersebut di atas. Dengan demikian jelaslah bahwa kita harus selalu mengedepankan sikap kehati-hatian dalam setiap tindak-tanduk kita di tengah-tengah masyarakat. Selain data tersebut terdapat pula babasan dan paribasa lainnya yang memiliki makna yang sama sebagai acuan kesantunan dalam berinteraksi sosial. Berikut ini beberapa contoh lainnya yang penulis dapatkan dari babasan dan paribasa Sunda.
(BAG.067) Dukun lintuh panyakit matuh
Kalah loba ngaluarkeun duit keur mayar dukun cageur mah henteu
(PAG. 071) Galagah kacaahan
Nganteur atawa ngalajur napsu lantaran kabaud ku batur
(BAG. 091) Hampang leungeun
Babari neunggeul
(BAG.113) Inggis ku bisi rempan ku sugan
Sieun ku rupa-rupa hal anu tacan tangtu kasorang
(PAG.311) Uncal kaauban surak
Ngadenge beja tacan sidik tuluy diandelkeun enya baé
(PAG.151) Kawas kuda leupas ti gedogan
Ngumbar kahayang lantaran geus euweuh nu ngahalang-halang

\section{Pola Tatakrama Masyarakat Sunda}

Dari pembahasan di atas, penulis menemukan kesamaan pola dalam setiap aspek tatakrama yang ditunjukan oleh babasan dan paribasa Sunda. Pola tersebut membentuk istilah baru yang penulis ambil dari karakter masing-masing aspek. Istilah yang dimaksud adalah terdiri atas lima kata, yaitu: wiwaha, wibawa, wirasa, wirahma, dan wiraga. Kemudian kelima istilah itu membentuk pola tertentu yang penulis anggap sebagai pola lahirnya tatakrama bagi masyarakat Sunda berdasarkan babasan dan paribasa. Adapun pola tatakrama tersebut dapat dicermati di bawah ini. 


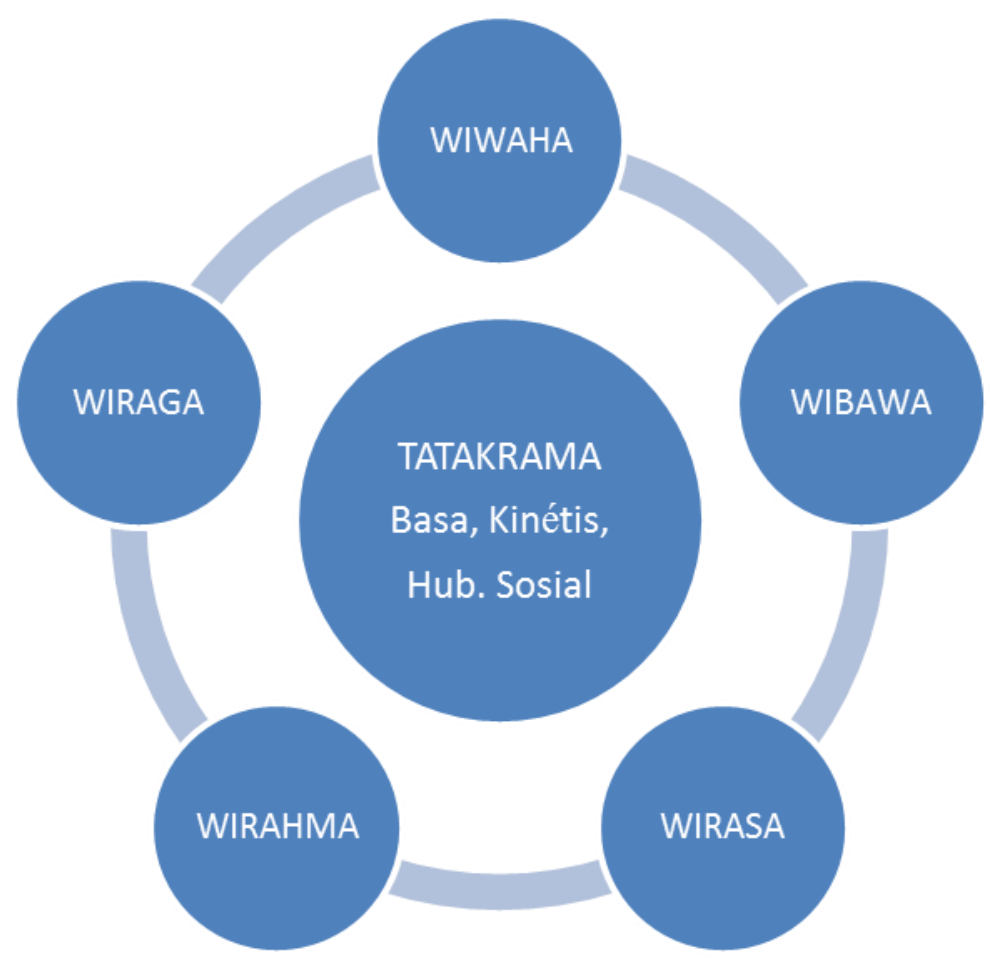

Bagan 1: Pola Tatakrama Masyarakat Sunda

Berdasarkan pola tersebut tergambar bagaimana tatakrama bahasa, kinetis, dan hubungan sosial saling berkaitan satu sama yang lainnya. Artinya bahwa ketiga aspek tatakrama tersebut harus hadir bersamaan dalam satu kegiatan interaksi sosial dengan kesantunan yang berwiwaha, berwibawa, berwirasa, berwirahma, dan berwiraga. Kesantunan berwiwaha menunjukan keharusan dalam menimbang-nimbang bahasa, kinetis, dan hubungan sosial sebelum berinteraksi sosial. Kesantunan berwibawa memiliki makna agar selalu menjaga kehormatan diri, orang lain, dan lingkungan dimana kita berinteraksi baik dalam berbahasa, kinetis, maupun berinteraksi. Kesantunan berwirasa adalah menunjukan agar kita senantiasa mengedepankan dan memperhatikan perasaan, merasakan, dan berperasaan dalam bertutur kata, bertindak, dan berinteraksi. Selanjutnya kesantunan berwirahma memiliki makna agar kita senantiasa menjaga kewirahmaan atau keharmonisan yang indah ketika kita berinteraksi baik melalui bahasa, tindakan, maupun pergaulan sosial. Dan yang terakhir adalah kesantunan berwiraga, memiliki makna agar kita senantiasa menempatkan diri kita, menghargai orang lain, dan lingkungan tempat kita berinteraksi tanpa harus saling menyakiti dan merugikan satu sama yang lain.

\section{SIMPULAN}

Dengan demikian maka dapat disimpulkan bahwa dalam babasan dan paribasa Sunda yang merupakan idiom bagi masyarakat Sunda terkandung nilai-nilai kesantunan sosial yang dapat dijadikan pedoman terciptanya lingkungan sosial yang seimbang dan bernilai. Kesantunan itu hendaknya lahir secara bersamaan dalam bentuk tutur kata atau bahasa, prilaku, dan hubungan sosial masyarakat. Dengan pola tatakrama yang muncul dari babasan dan paribasa maka diharapkan masyarakat (Sunda) tidaklah sulit untuk menjadi pribadi-pribadi yang santun dan memiliki nilai. 


\section{PUSTAKA RUJUKAN}

Danandjaja. (2007). Foklor Indonesia. Jakarta: PT Pustaka Utama Grafiti

Djundjunan. (2011). Etika jeung Tatakrama Sunda. Bandung: Sonagar press

Rachim. (1983). Etiket dan Pergaulan. Jakarta: PT.Karya Nusantara

Sudaryat. (2015). Wawasan Kesundaan. Bandung: JPBD FPBS UPI
Von Magnis. (1985). Etika Umum

Yudibrata SPk. (1984). Bagbagan makena basa. Bandung: CV. Geger Sunten

\section{UCAPAN TERIMAKASIH}

Terima kasih saya sampaikan kepada penyunting jurnal Lokabasa yang telah memuat tulisan ini. Dengan dimuatnya tulisan ini semaga ada manfaatnya. 